\title{
An Esthetics Rehabilitation with Computer-aided Design/ Computer-aided Manufacturing Technology
}

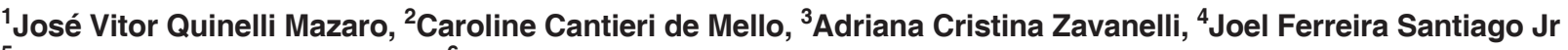 \\ ${ }^{5}$ Andressa Paschoal Amoroso, ${ }^{6}$ Eduardo Piza Pellizzer
}

\begin{abstract}
Aim: This paper describes a case of a rehabilitation involving Computer Aided Design/Computer Aided Manufacturing (CADCAM) system in implant supported and dental supported prostheses using zirconia as framework.
\end{abstract}

Background: The CAD-CAM technology has developed considerably over last few years, becoming a reality in dental practice. Among the widely used systems are the systems based on zirconia which demonstrate important physical and mechanical properties of high strength, adequate fracture toughness, biocompatibility and esthetics, and are indicated for unitary prosthetic restorations and posterior and anterior framework.

Case description: All the modeling was performed by using CAD-CAM system and prostheses were cemented using resin cement best suited for each situation.

Conclusion: The rehabilitation of the maxillary arch using zirconia framework demonstrated satisfactory esthetic and functional results after a 12-month control and revealed no biological and technical complications.

Clinical significance: This article shows the important of use technology CAD/CAM in the manufacture of dental prosthesis and implant-supported.

Keywords: Computer Aided Design/Computer Aided Manufacturing, Dental prosthesis, Dental implants, Mouth rehabilitation, Case reports.

How to cite this article: Mazaro JVQ, Mello CC, Zavanelli AC, Santiago JF Jr, Amoroso AP, Pellizzer EP. An Esthetics Rehabilitation with Computer-aided Design/Computer-aided Manufacturing Technology. J Contemp Dent Pract 2014;15(4): 506-512.

Source of support: Nil

Conflict of interest: None declared

\footnotetext{
${ }^{1,3}$ Assistant Professor, ${ }^{2} \mathrm{PhD}$ Student, ${ }^{4}$ Professor

${ }^{6}$ Adjunct Professor, ${ }^{5} \mathrm{MSc}$ Student

1-3,5,6 Department of Dental Materials and Prosthodontics UNESP - Universidade Estadual Paulista, Sao Paulo, Brazil

${ }^{4}$ Department of Health Sciences, University of Sacred HeartUSC, São Paulo, Brazil
}

Corresponding Author: José Vitor Quinelli Mazaro, Assistant Professor, Department of Dental Materials and Prosthodontics UNESP - Universidade Estadual Paulista, Sao Paulo, Brazil Phone: 551836363246, e-mail: zevitormazaro@foa.unesp.br

\section{INTRODUCTION}

The metal-free restorations were introduced with great success in dentistry for presenting a combination of peculiarities, such as their excellent mechanical properties and biocompatibility, which together fulfill the purpose of restoring function, and simultaneously ensure fundamental esthetics requirements on oral rehabilitation. ${ }^{1-3}$ With the advent of digital era and the emergence of Computer Aided Design/Computer Aided Manufacturing technology, ceramic restorations could be automated, with reduced production duration as well as more accurate adjustment of prosthetic pieces $^{1,4-9}$ and increased use of ceramics with high crystalline content ${ }^{10}$ especially zirconia.

With the progress of dental materials and techniques, CAD-CAM system currently allows the manufacture of inlays, onlays, full crowns, fixed prostheses, implant abutments ${ }^{1,7}$ and have become increasingly common in dental routine with the improvement of in-office systems.

It is a fact that the systems based on zirconia present, beyond the esthetic factors, high strength and radiopacity, $3,11-14$ plaque accumulation reduction and low thermal conductivity, ${ }^{15}$ resembling the natural teeth and for this reason they have become a standard considered whenever as possible in full crowns rehabilitations. ${ }^{14}$

Thus, this study aims to report a case in which the treatment of choice for the rehabilitation of the patient was the manufacture of ceramic prosthetic devices made by CAD-CAM system. The particularities surrounding the case from planning to installation and control will be described.

\section{CASE DESCRIPTION}

\section{Treatment Planning}

A 52-year-old female patient came to the dental clinic with the main purpose of replacing the former prosthetic restorations in the maxillary arch. During the anamnesis, it was observed that the patient was unsatisfied mainly with dental esthetics and after performing clinical and radiographic examination, it was found that the full crowns of the teeth $11,12,13,21,22,23$ were maladapted and with color alteration. In addition to the loss of dental elements 
14 and 15 by root fracture, unsatisfactory restorations in the elements 16, 24, 25 and 26 were also found (Figs 1A and B).

After a discussion between the staff and the patient, the proposed treatment was: metal-free full crowns on teeth $11,12,13,21,22,23$, implant crowns on teeth 14 and 15 overlays on teeth 24 and 25, and onlays on teeth 16 and 26 . The old crowns and restorations were removed, the preparations were made on remnants of dental elements, and two implants were placed (SIN Implant Systems ${ }^{\circledR}$, Sao Paulo, SP, Brazil) in the region of teeth 14 and 15 after the extraction of the fractured roots.
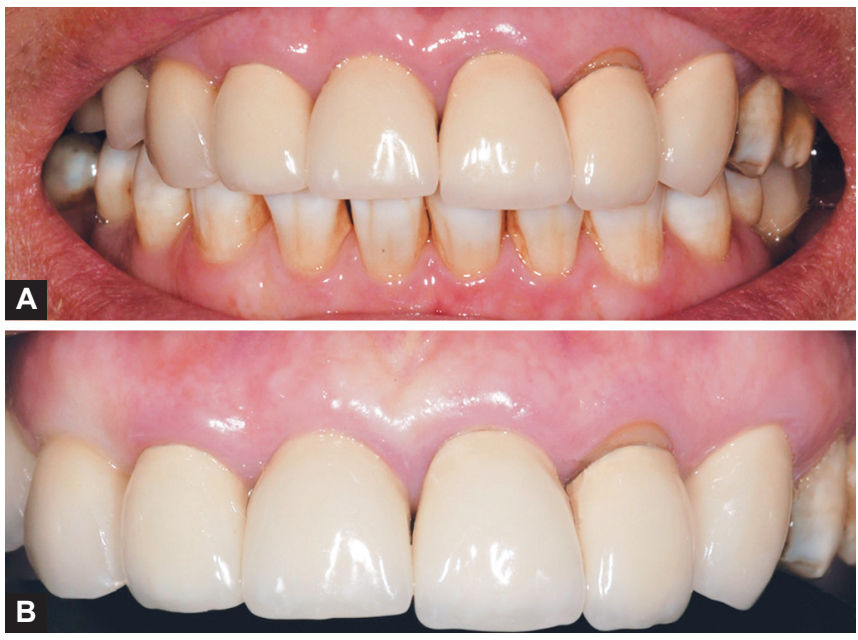

Figs $1 \mathrm{~A}$ and $\mathrm{B}$ : Initial case

\section{Clinical Treatment}

To remove the fixed prosthodontics and preparing the teeth, patient was anesthetized with $3 \%$ citocaine $\left(\right.$ Cristália ${ }^{\circledR}$, Itapira, Sao Paulo, Brazil). The preparation for full crowns respected occlusal convergence with inclinations of about $10^{\circ}$, rounded shoulder finish line with $1.2 \mathrm{~mm}$ in depth, axial and occlusal/incisal reduction of $2.0 \mathrm{~mm}$ and rounded corners, always being careful to standardize the preparation thus ensuring resistance to the restoration. In the preparation for onlay and overlay a minimum occlusal reduction of $1.5 \mathrm{~mm}$ was performed on the non-functional cusps and $2.0 \mathrm{~mm}$ on functional cusps, verifying a space from 2.0 to $2.5 \mathrm{~mm}$ between the pulp wall and cusp tip of the antagonist tooth, isthmus wear with $2.0 \mathrm{~mm}$ in depth, proximal preparations with at least 1.5 to $2.0 \mathrm{~mm}$ in depth and axial walls around $10^{\circ}$ to $20^{\circ}$ expulsive. The implants transferees were placed and joined with self-curing red acrylic resin (Duralay ${ }^{\circledR}$, Cotia, Sao Paulo, Brazil) in order to attach them to each other and to be molded along with the preparations (Figs 2A and $\mathrm{B})$. The impression was performed by the double cord technique, where the prepared teeth received retraction cords (Ultradent ${ }^{\circledR}$, South Jordan, UT, USA) for gingival retraction, firstly placing the thinner cord (Ultrapack $\# 000$, Ultradent ${ }^{\circledR}$, South Jordan, UT, USA) in gingival sulcus followed by the thicker one (Ultrapack \#00, Ultradent ${ }^{\circledR}$, South Jordan, UT, USA), left on position for about 3 minutes. At the time of
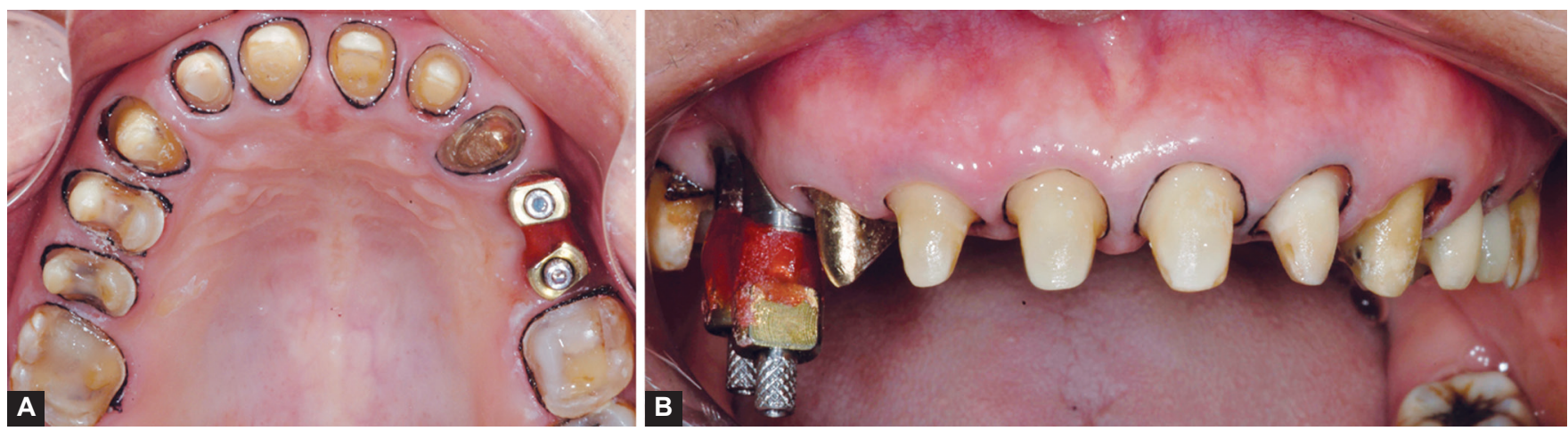

Figs $2 \mathrm{~A}$ and $\mathbf{B}$ : Implants transferees installed and retraction cords in position for impression

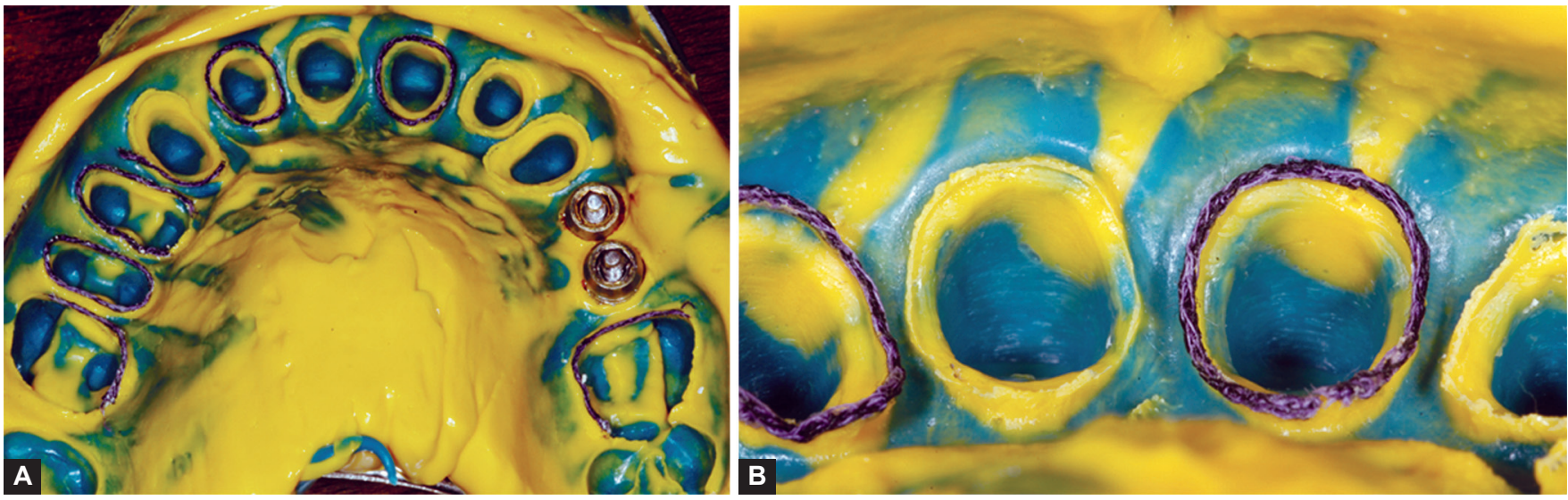

Figs $3 \mathrm{~A}$ and $\mathbf{B}$ : Mold with retraction cord. Note the reproduction fidelity of the preparation margins 
impression, the second cord was removed taking gingiva away enough from the finish line of the preparation. After the selection of perforated and adapted tray, it was charged with the dense paste while the fluid paste (Honigum-DMG ${ }^{\circledR}$, Hamburg, Germany) was injected around the preparation and transferees. Following material polymerization, the whole conjunct was removed from mouth and a detailed analysis of the mold was performed aiming at a faithful copy of all structures, mainly the preparations contour (Figs 3A and B).

Based on the impression two casts were obtained: one for scanning and die and a rigid one for the individualization of contact points. The model die was scanned (Scanner Cerec $3^{\circledR}$, Bensheim, Hessen, Germany) and the design of prosthetic pieces was obtained virtually, determining the CAD phase of the system and sent to the milling machine (CAM phase), in order to manufacture the framework of the prosthodontics pieces through milling ceramic blocks, including the prosthetic implant abutments (Figs 4A to D). For the design of framework through software, the opposite arch and intermaxillary registry were also scanned, allowing the mounting of models three-dimensionally in the program.

In full crowns, implant abutments and overlays, the ceramic of choice for framework was CAD-CAM system Zirconium Dioxide (IPS e.max ZirCAD blocks - IvoclarVivadent $^{\circledR}$, Schaan, Liechtenstein), while the onlays of teeth 16 and 26 were made with lithium disilicate ceramic (IPS e.max Press - Ivoclar-Vivadent, Sao Paulo, Brazil), and all framework were laminated with nanofluorapatite ceramic (IPS e.max Ceram-Ivoclar-Vivadent ${ }^{\circledR}$, Schaan, Liechtenstein) (Figs 5A and B). The lithium disilicate was chosen for onlay restorations, because they are acid-sensitive ceramics, thus enabling greater adhesion to the dental substrate (Figs 6A and B).

After finalizing the prosthodontic pieces (Figs 7A and B; Figs $8 \mathrm{~A}$ to $\mathrm{C}$ ), their excellent adaptation could be observed in models, and the cervical adaptation and intensity of proximal contacts were also evaluated in mouth.

The cementation of zirconia pieces was performed with primer and self-curing resin cement for zirconia (Multilink - Ivoclar-Vivadent ${ }^{\circledR}$, Schaan, Liechtenstein), and implant supported prostheses were screwed. The sequence of adhesive cementation for acid-resistant ceramic (Zirconia), occurred as follows: piece preparation, one-cleaning the inside of the piece with alcohol; washing and drying, two - application of primer with phosphate monomer (Zirconia Primer - Multilink - Ivoclar-Vivadent ${ }^{\circledR}$, Schaan, Liechtenstein). Tooth preparation: one - prophylaxis with pumice and water; washing and drying, two - active application (20 seconds) of primer A + B (Multilink - IvoclarVivadent $^{\circledR}$, Schaan, Liechtenstein), three - evaporation of the solvent. The self-curing cement (Multilink - IvoclarVivadent $^{\circledR}$, Schaan, Liechtenstein) was proportioned and spatulated according to the manufacturer's instructions and carried to the prosthetic pieces. After laying the pieces the excesses were removed and the polimerization of the resin cement was completed. ${ }^{16}$
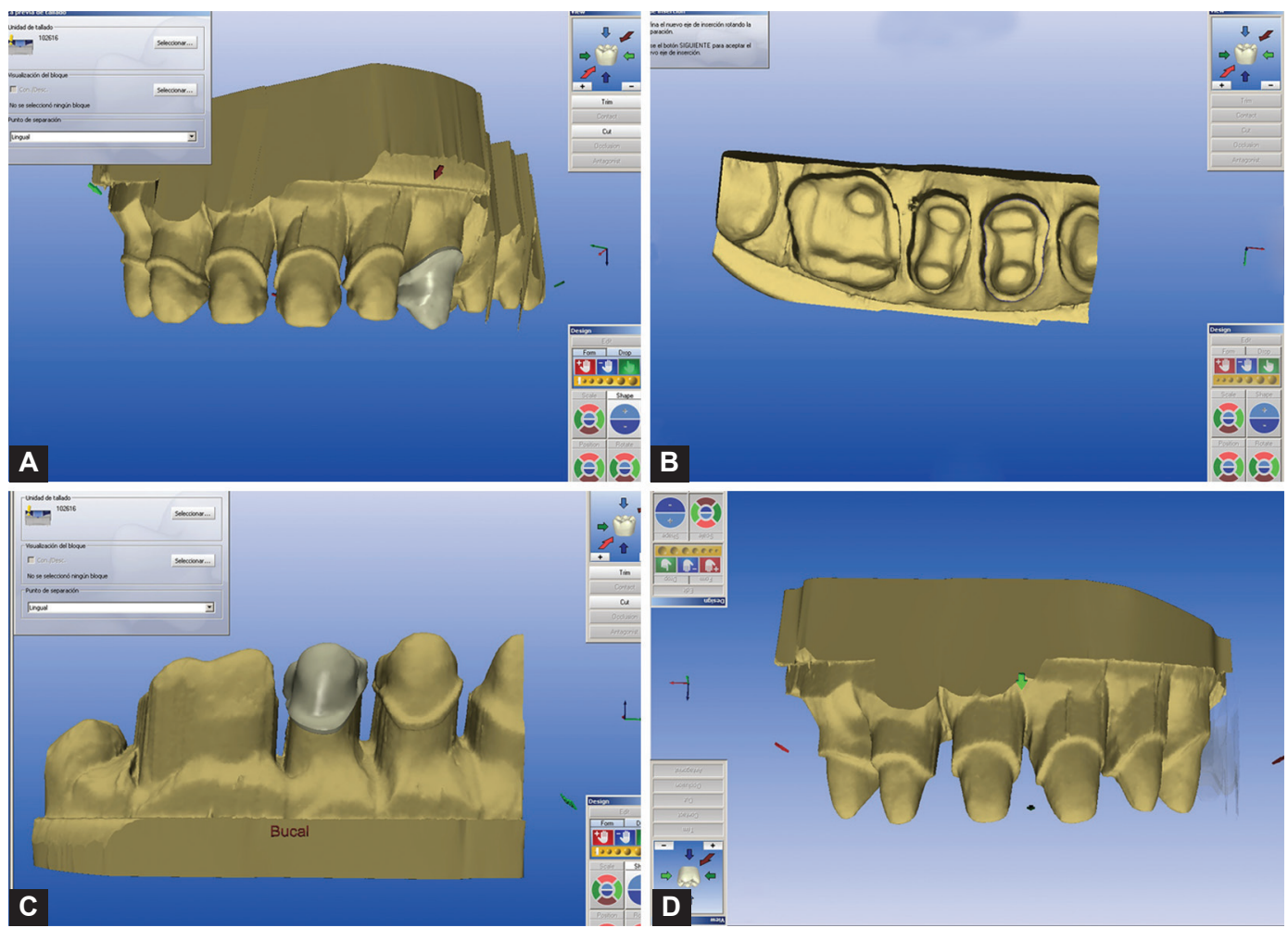

Figs 4A to D: Scanning and manufacturing virtual framework from the CAD/CAM system 

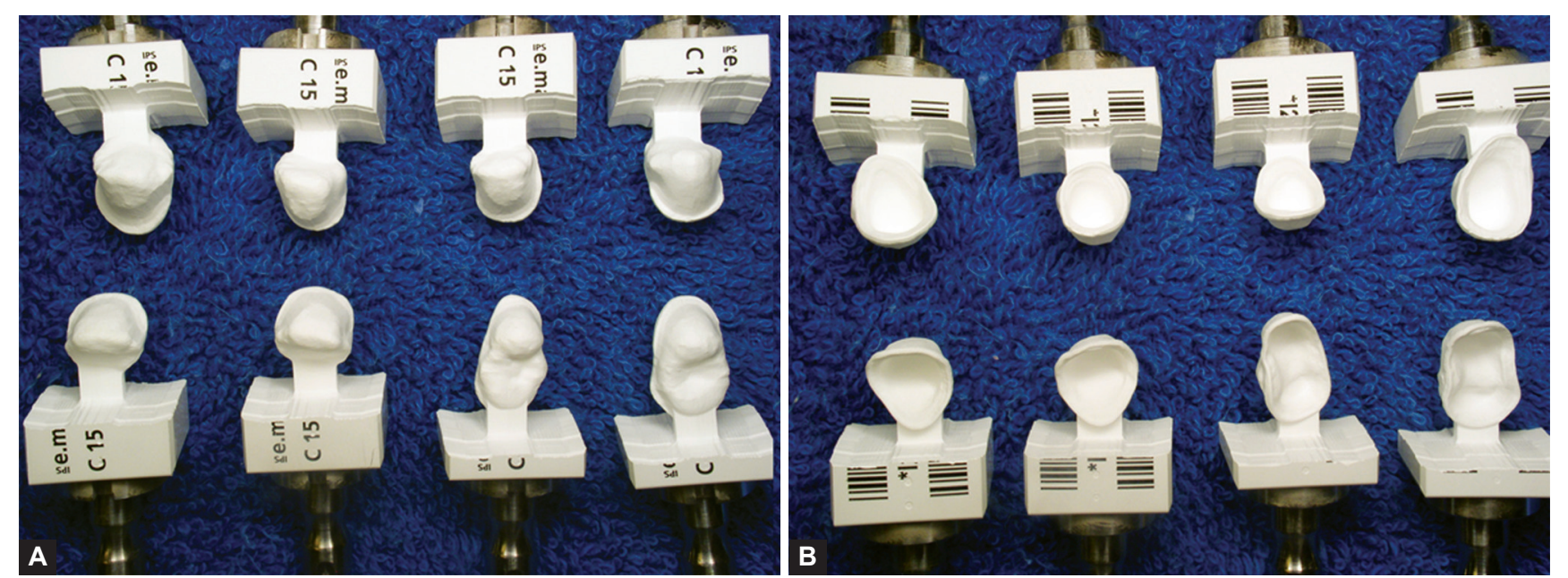

Figs 5A and B: External and internal surface of framework milled in ceramic blocks ZirCAD. (Ivoclar-Vivadent ${ }^{\circledR}$, Schaan, Liechtenstein)
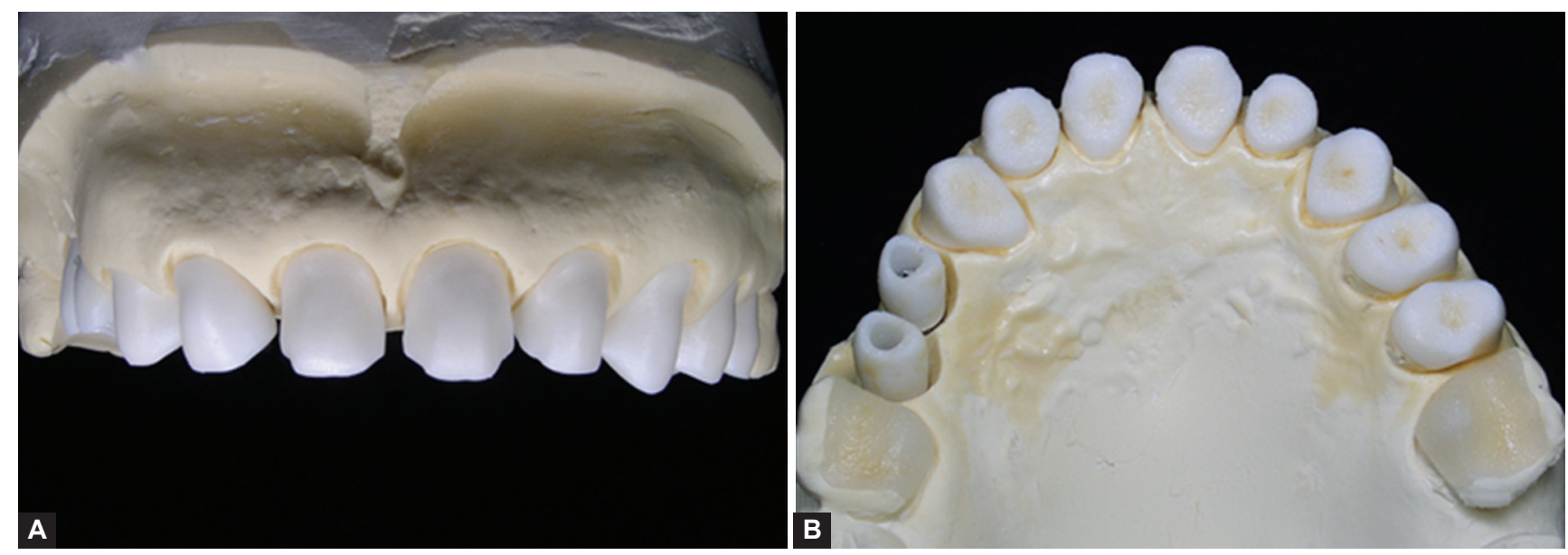

Figs $6 A$ and $B$ : Framework of e.max ZirCAD and e.max Press in the position on the models

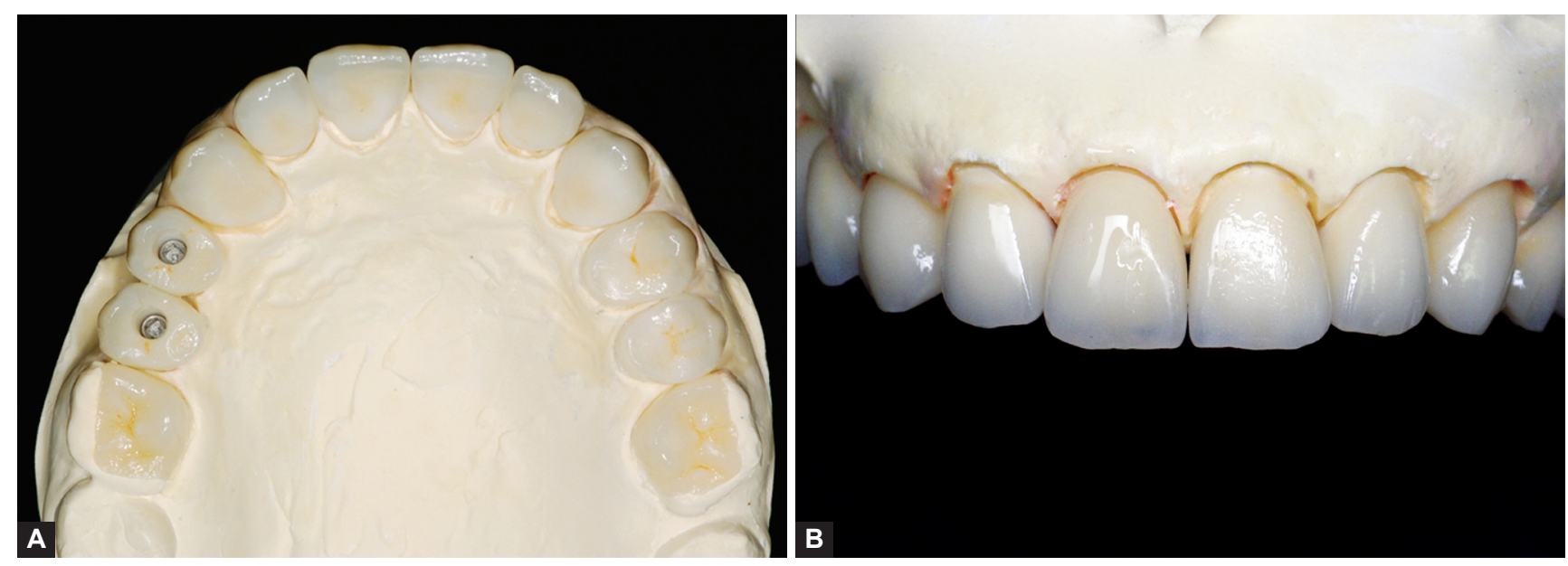

Figs 7A and B: Pieces in position on the models, after final application of glaze

The sequence of adhesive cementation for acid sensitive ceramics (Lithium disilicate) of elements 16 and 26 occurred as follows: Piece preparation; one-application of $10 \%$ porcelain fluoridric acid (Dentsply ${ }^{\circledR}$, York, Pennsylvania, USA) for 20 seconds on the inner surface of the pieces; washing with water and drying, two - ultrasonic bath for 5 minutes to remove the precipitated silica; washing and drying, three - application of Silane (Monobond S - Ivoclar-Vivadent ${ }^{\circledR}$, Schaan, Liechtenstein) awaiting 3 minutes. Dental substrate preparation (16 and 26): one $-37 \%$ phosphoric acid for 30 seconds on enamel and for 15 seconds on dentine (Total Etch - IvoclarVivadent ${ }^{\circledR}$, Schaan, Liechtenstein); washing and drying, two - application of the adhesive system; evaporation of the 


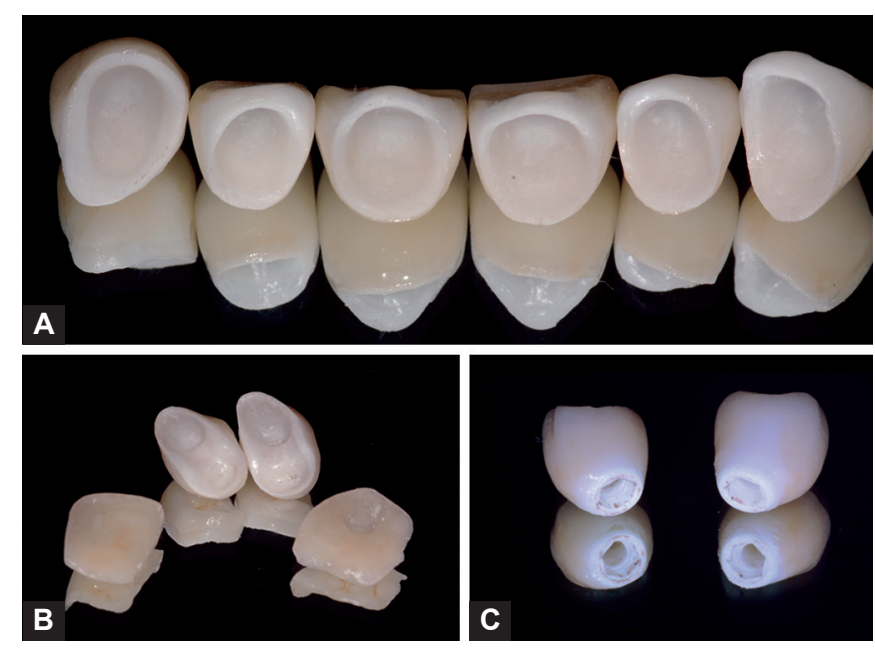

Figs 8A to C: Ceramic crowns finalized

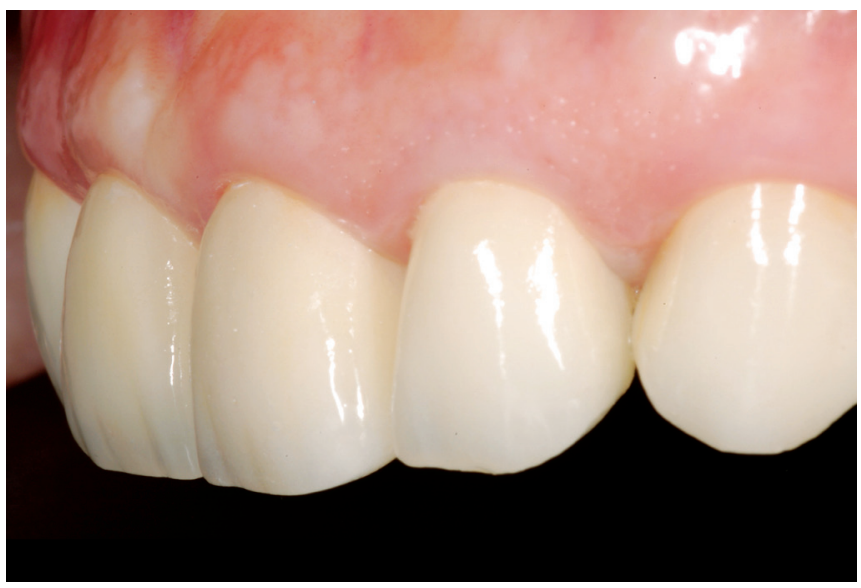

Fig. 10: Finished aspect of cemented crowns (lateral view)

solvent, three - photopolymerization for 20 seconds. After restorative and dental substrates preparation, Variolink II resin cement (Ivoclar-Vivadent ${ }^{\circledR}$, Schaan, Liechtenstein) was proportioned and spatulated according to the manufacturer's instructions. With the prosthetic pieces in place, any cement excess was removed and photopolymerization was performed for 40 seconds per face. Furthermore, on all interfaces oxygen inhibitor gel was applied (Liquid Strip Ivoclar-Vivadent ${ }^{\circledR}$, Schaan, Liechtenstein) and polymerized again for 40 seconds per face. Occlusal adjustments were carefully measured and the patient was guided about hygiene care. At the end of cementation, it can be observed gingival health maintained by optimal adaptation of the prosthetic pieces to the preparation, as well as the excellent natural emergence profile provided by these prosthetic devices (Figs 9 to 11). ${ }^{17}$

\section{DISCUSSION}

Among the metal-free materials used for the manufacture of fixed partial prostheses, ceramics and especially zirconia have become one of the prevailing among a variety of rehabilitations that use CAD-CAM technology, ${ }^{18}$ allowing

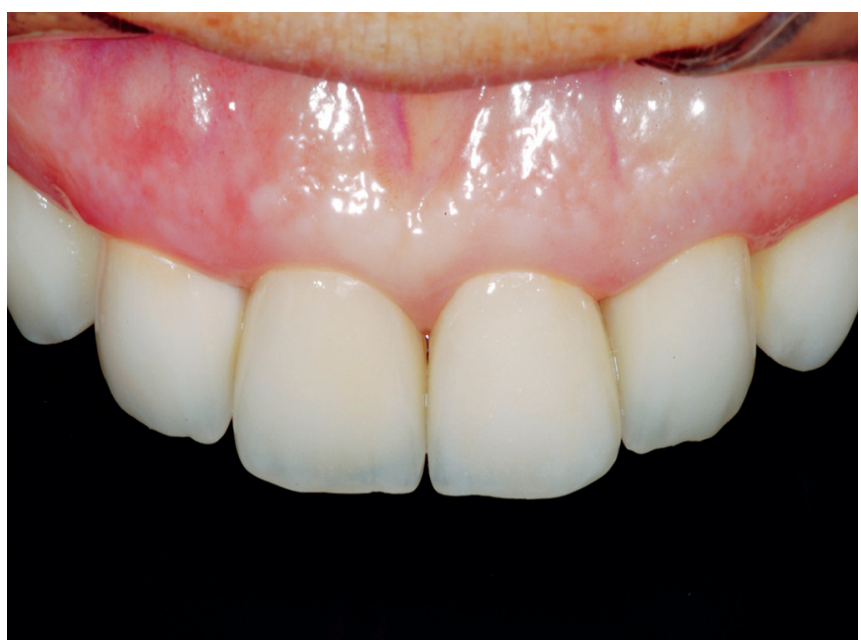

Fig. 9: Finished aspect of cemented crowns (front view)

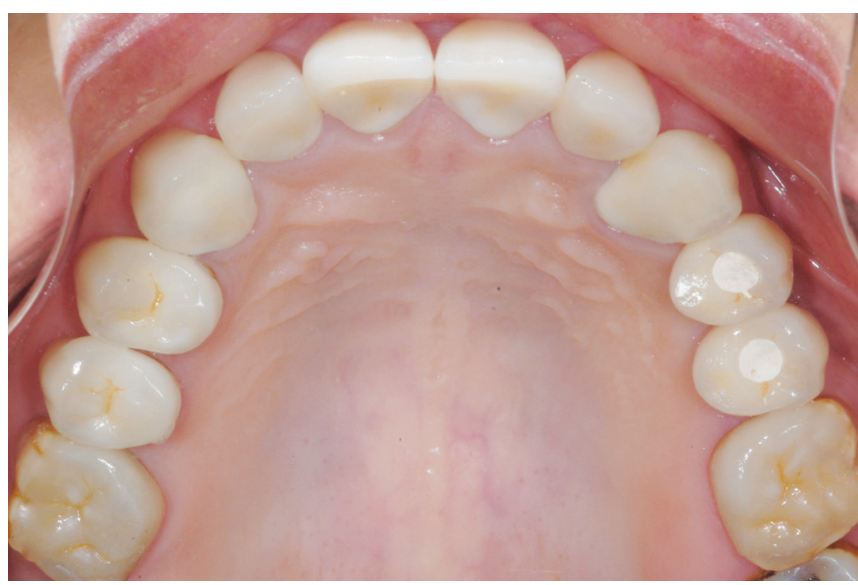

Fig. 11: Finished aspect of cemented crowns (occlusal view)

final characterization by ceramicist or full use of the structure of zirconia. In a systematic review ${ }^{19}$ showed that short-term clinical data suggest that zirconia fixed prostheses can be considered viable and data still limited suggest that zirconia resulted in better clinical outcome when compared to conventional technique. Furthermore, the framework made of zirconia provides an improved potential to withstand masticatory loading, since the resistance limit of the material is above $1000 \mathrm{MPa}^{11,14}$ The literature also emphasizes that zirconia components can distribute the stresses better in comparison with titanium abutment. ${ }^{11}$

Marginal adaptation of these ceramics has been considered crucial in successful rehabilitation. In a randomized controlled trial ${ }^{20}$ compared metal-ceramic crowns and full porcelain crowns and revealed that the biological complications due to lower marginal adjustment were observed in the full porcelain crowns, and this could be related to the pre-sintering zirconia coppings. Additionally, a prospective study $\mathrm{y}^{21}$ of 5 years in 213 patients who received implants with zirconia abutments, and revealed predictability rates above $95 \%$, however there is concern about screw loosening, screw fractures and pillars, what requires correct 
indication. On the other hand, studies using titanium as a base material showed screw loosening rates of $9.1 \%{ }^{22}$ and fractures of screws and abutments of $3.1 \% .^{23}$

Longitudinal studies are still scarce in the literature, but exhibit high success rates. A recent study ${ }^{24}$ performed a follow-up study of 7 years in 28 patients who received prostheses with zirconia in the posterior region; the authors stated that zirconia framework can be used as an acceptable material for rehabilitation in the anterior and posterior regions, however the authors recommend that the long-term evaluations are a fundamental requirement for accurate zirconia indications. Besides, a longitudinal analysis ${ }^{25}$ of 102 zirconia crowns also suggest knife-edge marginal design, which allows a performance similar to other kinds of preparations, such as chamfer ${ }^{26}$ and deep chamfer ${ }^{27,28}$ however this approach is not yet a consensus in the literature, and suggests more randomized controlled trials. ${ }^{25}$

The current clinical case revealed no technical problems, but the most common technical problem of prostheses based on zirconia is total or partial fracture, and may be related to minor $(11.6 \%)$ and moderate fractures $(17.6 \%)$; the reasons for failure have been related to defects in material, manufacturing error and inappropriate handling in the laboratory. $^{29}$

Important factors that should be taken into consideration are related to occlusal adjustment and accurate parafunctional activities controlling. ${ }^{14}$ Furthermore, the masticatory movements can cause small cracks that penetrate the zirconia over time and the exposure to the oral cavity can spread micro-fractures. ${ }^{18}$ However, in a systematic review ${ }^{19}$ reported low rates of fracture of zirconia cores and in addition show short-term data suggesting that fixed prostheses using zirconia can be considered viable.

\section{CONCLUSION}

The maxillary arch rehabilitation of the patient performed by CAD-CAM system (IPS e.max) demonstrated satisfactory esthetic and functional results, especially satisfying patient needs. In a 12-month control no technical complications were observed.

\section{CLINICAL SIGNIFICANCE}

This article shows the important use of CAD-CAM technology in the manufacture of dental prosthesis and implant- supported.

\section{ACKNOWLEDGMENTS}

The authors would like to thank Romanini Dental Prosthesis Laboratory - Londrina/PR for designing the prosthetic pieces and gently yielding the images of laboratory procedures performed for manufacturing the prostheses.

\section{REFERENCES}

1. Haralur SBI, Al-Faifi AH. Use of CAD/CAM in esthetic restoration of badly decayed tooth. Case Rep Dent 2012. 2012 Dec 5:608232.

2. Kim JH, Lee SJ, Park JS, Ryu JJ. Fracture load of monolithic $\mathrm{CAD} / \mathrm{CAM}$ lithium disilicate ceramic crowns and veneered zirconia crowns as a posterior implant restoration. Implant Dent 2013;22:66-70.

3. Yildiz C, Vanlioğlu BA, Evren B, Uludamar A, Ozkan YK. Marginal-internal adaptation and fracture resistance of CAD/ CAM crown restorations. Dent Mater J 2013;32:42-47.

4. Davidowitz G, Kotick PG. The use of CAD/CAM in dentistry. Dent Clin North Am 2011;55:559-570.

5. Miyazaki T, Hotta Y. CAD/CAM systems available for the fabrication of crown and bridge restorations. Aust Dent J 2011; 56:97-106.

6. Alhashim A, Kamel M, Brackett WW. Four-year follow-up of the rehabilitation of a mandibular arch with a cementable zirconia-reinforced fixed dental prosthesis: a clinical report. J Prosthet Dent 2012;108:138-142.

7. Galhano GÁ, Pellizzer EP, Mazaro JV. Optical impression systems for CAD-CAM restorations. J Craniofac Surg 2012;23: e575-e579.

8. Stawarczyk B, Basler T, Ender A, Roos M, Ozcan M, Hämmerle C. Effect of surface conditioning with airborne-particle abrasion on the tensile strength of polymeric CAD/CAM crowns luted with self-adhesive and conventional resin cements. J Prosthet Dent 2012;107:94-101.

9. Batalha-Silva S, deAndrada MA, Maia HP, Magne P. Fatigue resistanceand crack propensity of large MOD compositeresin restorations: direct versus CAD/CAM inlays. Dent Mater 2013;29:324-331.

10. Borba M, Cesar PF, Griggs JA, Della Bona Á. Adaptation of allceramic fixed partial dentures. Dent Mater 2011;27:1119-1126.

11. Çaglar A, Bal BT, Karakoca S, Aydın C, Yılmaz H, Sarısoy $\mathrm{S}$. Three-dimensional finite element analysis of titanium and yttrium-stabilized zirconium dioxide abutments and implants. Int J Oral Maxillofac Implants 2011;26:961-969.

12. Marchack BW, Sato S, Marchack CB, White SN. Complete and partial contour zirconia designs for crowns and fixed dental prostheses: a clinical report. J Prosthet Dent 2011;106:145-152.

13. Papaspyridakos P, Lal K. Computer-assisted design/computerassisted manufacturing zirconia implant fixed complete prostheses: clinical results and technical complications up to 4 years of function. Clin Oral Implants Res 2013;24:659-665.

14. Engelberg B. Zirconia: clinical impressions. An in vivo comparison of the aesthetics of various zirconia crowns. Dent Today 2012 July;31(7):106-109.

15. Dittmer MP, Kohorst P, Borchers L, Stiesch-Scholz M. Finite element analysis of a four-unit all-ceramic fixed partial denture. Acta Biomater 2009;5:1349-1355.

16. Passos SP, Kimpara ET, Bottino MA, Júnior GC, Rizkalla AS. Bond strength of different resin cement and ceramic shades bonded to dentin. J Adhes Dent 2013 Oct;15(5):461-466.

17. Sasse M, Eschbach S, Kern M. Randomized clinical trial on single retainer all-ceramic resin-bonded fixed partial dentures: influence of the bonding system after up to 55 months. J Dent 2012;40:783-786. 
18. Giordano R 2nd. Zirconia: a proven, durable ceramic for esthetic restorations. Compend Contin Educ Dent 2012;33:46-49.

19. Raigrodski AJ, Hillstead MB, Meng GK, Chung KH. Survival and complications of zirconia-based fixed dental prostheses: a systematic review. J Prosthet Dent 2012;107:170-177.

20. Hosseini M, Worsaae N, Schiodt M, Gotfredsen K. A 1-year randomised controlled trial comparing zirconia versus metalceramic implant supported single-tooth restorations. Eur J Oral Implantol 2011;4:347-361.

21. Kim SS, Yeo IS, Lee SJ, Kim DJ, Jang BM, Kim SH, Han JS. Clinical use of alumina-toughened zirconia abutments for implant-supported restoration: prospective cohort study of survival analysis. Clin Oral Implants Res 2013;24:517-522.

22. Binon PP. Implants and components: entering the new millennium. Int J Oral Maxillofac Implants 2000;15:76-94.

23. Behr M, Lang R, Leibrock A, Rosentritt M, Handel G. Complication rate with prosthodontic reconstructions on ITI and IMZ dental implants. Internationales Team für Implantologie. Clin Oral Implants Res 1998;9:51-58.
24. Lops D, Mosca D, Casentini P, Ghisolfi M, Romeo E. Prognosis of zirconia ceramic fixed partial dentures: a 7-year prospective study. Int J Prosthodont 2012;25:21-23.

25. Poggio CE, Dosoli R, Ercoli C. A retrospective analysis of 102 zirconia single crowns with knife-edge margins. J Prosthet Dent 2012;107:316-321.

26. Encke BS, Heydecke G, Wolkewitz M, Strub JR. Results of a prospective randomized controlled trial of posterior $\mathrm{ZrSiO}_{4}$ ceramic crowns. J Oral Rehabil 2009;36:226-235.

27. Ortorp A, Kihl M, Carlsson G. A 3-year retrospective and clinical follow-up study of zirconia single crowns performed in a private practice. J Dent 2009;37:731-736.

28. Groten M, Huttig F. The performance of zirconium dioxide crowns: a clinical follow-up. Int J Prosthodont 2010;23:429431.

29. Salido MP, Martinez-Rus F, del Rio F, Pradies G, Ozcan M, Suarez MJ. Prospective clinical study of zirconia-based posterior four-unit fixed dental prostheses: four-year follow-up. Int J Prosthodont 2012;25:403-409. 